\title{
ANALYSIS OF THE GAZE BEHAVIOUR OF THE WORKER ON THE CARBURETOR ASSEMBLY TASK
}

\author{
Novie Susanto*) \\ Industrial Engineering Study Program, Faculty of Engineering, DiponegoroUniversitas \\ Jl. Prof. Soedharto, SH, Kampus Undip Tembalang, Semarang Indonesia 50275
}

\begin{abstract}
This study presents analysis of the area of interest (AOI) and the gaze behavior of human during assembly task. This study aims at investigating the human behavior in detail using an eye-tracking system during assembly task using LEGO brick and an actual manufactured product, a carburetor. An analysis using heat map data based on the recorded videos from the eye-tracking system is taken into account to examine and investigate the gaze behavior of human. The results of this study show that the carburetor assembly requires more attention than the product made from LEGO bricks. About $50 \%$ of the participants experience the necessity to visually inspect the interim state of the work object during the simulation of the assembly sequence on the screen. They also show the tendency to want to be more certain about part fitting in the actual work object.
\end{abstract}

Keywords: assembly; gaze behaviour; eye tracking system; cognitive

\section{Introduction}

Cognitive engineering has become an important aspect of production systems research. To improve productivity, safety and well-being, it is important to highlight the role of human cognition in future production systems. Most conventional production systems are designed with their focus on advanced technology and a strong emphasis on automation. Design for cognitive compatibility plays a vital role in these complex work systems regarding the improvement of joint performance and optimization in human-machine and human-robot interactions.

A solution is provided through the ergonomic design of human-robot interaction (HRI) with balanced automation. This approach features a high level of robotic automation offering a broad range of advantages (in terms of precision, control and reproducibility), without hindering the human operator in utilizing and developing his or her individual knowledge, skills and abilities. Hence, ergonomic HRI presents the most advantageous option for maintaining productivity and increasing flexibility while continuously optimizing and adapting the corresponding manufacturing processes.

To evaluate the effects of automation functions in a work system, the definition of the term "automation" is required. Automation is defined as "automatic control of the manufacture of a product through a number of successive stages; the application of automatic control to any branch of industry or science;

\footnotetext{
${ }^{*}$ Penulis Korespondensi. email: nophie_susanto@yahoo.com.sg
}

Jurnal Teknik Industri, Vol. X, No. 2, Mei 2015 by extension, the use of electronic or mechanical devices to replace human labor" (OED, 2010). Referring to the extended definition of automation, "human labor" in automated work systems is not habitually replaced. The role of human operators in highly automated systems is essential, especially to carry out various kinds of supervisory control tasks, or to intervene whenever errors occur (Mayer et al., 2012). Hence, future manufacturing systems should focus on the integration of human operators in the production environment according to his or her specific capabilities in problem solving, decision making and planning (Schlick et al., 2002).

Human workers fulfill an essential role in production systems and feature individual methods, strategies and procedures when carrying out their respective work tasks. In a joint cognitive system, they fulfill a combined role of operator and system supervisor. Therefore, they should be able to effectively make decisions, support the team in the work system and autonomously conduct actions, especially in situations critical to safety or quality. Thus "cognitive patterns", as high-level structures of cognitive control, are critical points in these work systems because a large part of system performance is dependent on human cognition. This human-oriented symbolic representation is used as a basis of cognitive planning and control system design. Conventional research in ergonomics often treats participant cognition as a static factor within the system. This conventional approach contradicts the user-centered design of human-robot systems where participants experience a change in cognitive processes through their contextualized learning experience with the robot(s). Changes in cognitive processes reflect the 

a heat map analysis. Figure 2 shows a different view on the experimental environment, in which the participant wears an eye-tracking system.

The study is conducted with 13 participants from Indonesia (range of ages $28.5 \pm 4.7$ years old), which coincides with the prediction study (see Susanto et al, 2014 for the further detail).
The eye-tracking system considers four area of interest (AOI) in its environment. AOI 1 concerns the screen for assembly guidance visualization. AOI 2 covers the predicted LEGO brick or carburetor part. AOI 3 encompasses the assembly work area, while AOI 4 is designed to track eye activity in the completed assembly group area. Figure 3 presents the AOI in this study.

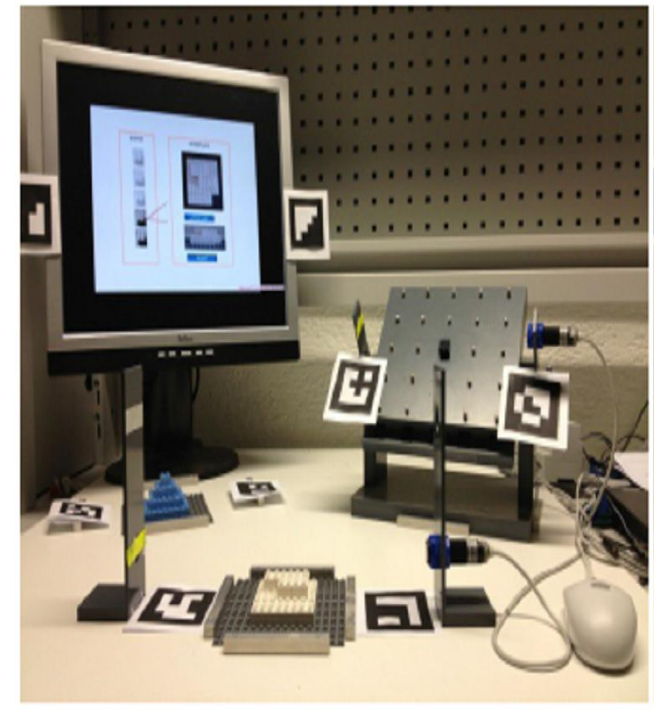

(a)

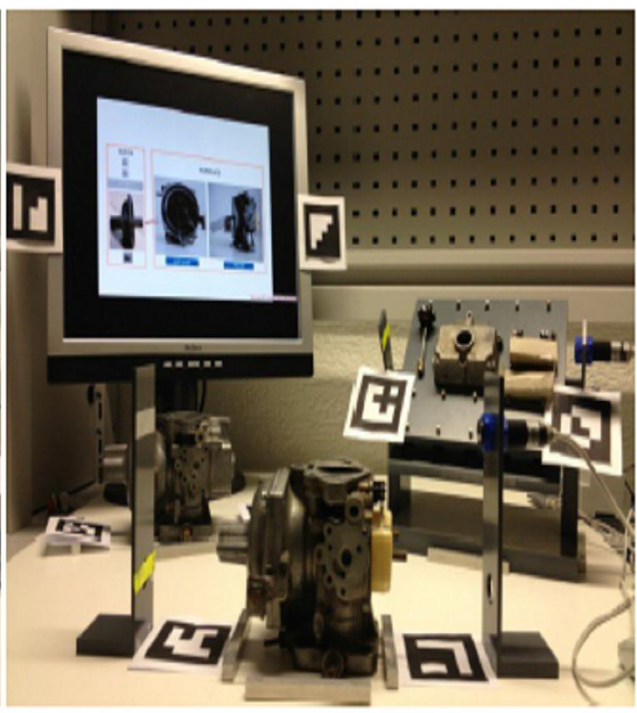

(b)

Figure 1. Environment of the study (a) for the product made from LEGO bricks (b) for the carburetor

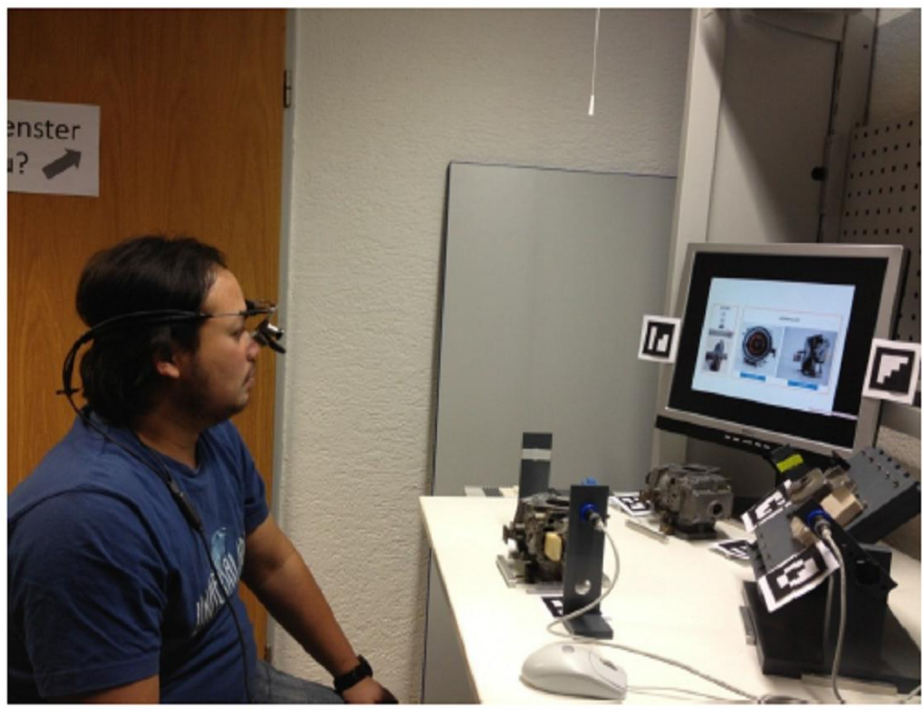

Figure 2. Environment of the study with the eye-tracking system 


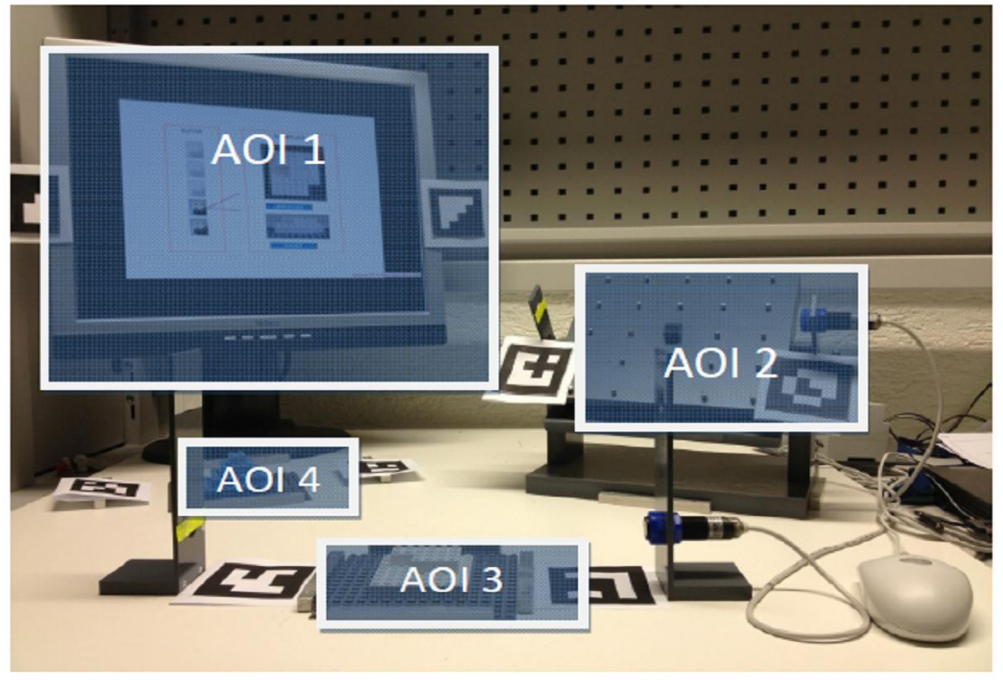

Figure 3. The areas of interest in this study

\section{Procedure}

The procedure of this study 2 is divided into three main phases:

(1) Personal data collection and training under study conditions

First is the anonymized collection of personal data (e.g., age, education level, prior experience with the assembly task and LEGO assembly). The participant is introduced to the apparatus, the study environment the interim state and the completed object assembly group after the personal data are collected.

(2) Calibration of the eye-tracking system

Secondly, the calibration of the eye-tracking system is performed through the following procedures:

- Placing the head unit of the eye-tracking system on the participant's head.

- Starting the Dikablis recorder program and initiating eye detection.

- Calibrating the optical tracers based on standard areas.

(3) Data acquisition

The next phase consists of illustration and explanation of the assembly task to the participant. These explanations are visible on the monitor. After this, the participant is expected to notice the assembly pattern regarding the sequence of the LEGO brick or carburetor part placement and predict the next position of the LEGO brick or carburetor part. After the prediction task, the participants should examine some assessments that visualized in monitor.

In total, there are 12 prediction tasks divided into two sessions (6 tasks for first session using LEGO brick and 6 tasks for the second session for carburetor assembly) with a randomized order of assembly sequences. The duration per study is approximately 60 minutes for each person including personal data collection, eye-tracking system calibration and performing the required tasks.

\section{Result and Discussion \\ Area of Interest (AOI)}

The eye-tracking system was used to examine the area of interest (AOI) during the execution of assembly tasks. As shown in Figure 3, there are four AOI in Study 2. The data of fixation duration is obtained from the recorded video files based on the eye pupil movement and heat map analysis using D-Lab Analysis software. Figures 4 and 5 show a heat map analysis of the assembly of the product made from LEGO bricks and the carburetor respectively.

\section{Gaze Behavior}

The gaze behavior data is analyzed with respect to the working area in the recorded video files. The participants followed a similar pattern regarding gaze behavior during this study, as shown in Figure 6.

Participants generally start to focus on AOI 1 that visualizes the assembly sequences. After the simulation is finished, participants switch to the AOI into the part area (AOI 2). Attention is then shifted to AOI 3, which is the assembly work area. Afterwards, the participants return to AOI 1 to complete the subjective evaluation of the task. There is only a low attention focus from participants on AOI 4. However, during this study, there are also different gaze behaviors, as shown in Table 1 .

According to Table 1, the carburetor assembly requires more attention in AOI 3 than the product made from LEGO bricks. About $50 \%$ of the participants experience the necessity to check the interim state of the work object during the simulation 
of the assembly sequence on the screen. The frequency of attention shifting from AOI 1 to AOI 3 during the visualization varies between one and up to four times. Participants tend to ensure the equivalency of the actual work object with the simulated object on the screen. This fact is concomitant with Nisbett and Norenzayan (2002) regarding the cognitive processes of Easterners. In this study, participants tend to pay attention to the relationship between the actual work object and the visualized object on the screen.

The difference of gaze behavior type, as shown in fifth gaze behavior in Table 1, is indicated when the presentation of assembly sequence is finished, and the participants are expected to determine the next assembly part. The participants have less confidence in making decisions about the selection of the next part. They require certainty on the selected fitting part for the actual object work. Thus, the participants often shift their attention to AOI 3 before determining the selected part. The discussion of control and confidence levels of the participants during decision making is also in accordance with the findings of Nisbett and Norenzayan (2002) regarding the Easterner behavior.

The practical implementation of this study can be applied on analyzing direct human-robot interaction. Based on the result of this study, it is known that human operator had a tendency to ensure the similarity between the examples visualized in the display with the real product. In direct human-robot interaction, human operator is expected to pay attention on the assembly guidance and the robot behavior in the similar proportion. By doing so, the safety and the performance of the human operator within work process can be improved.

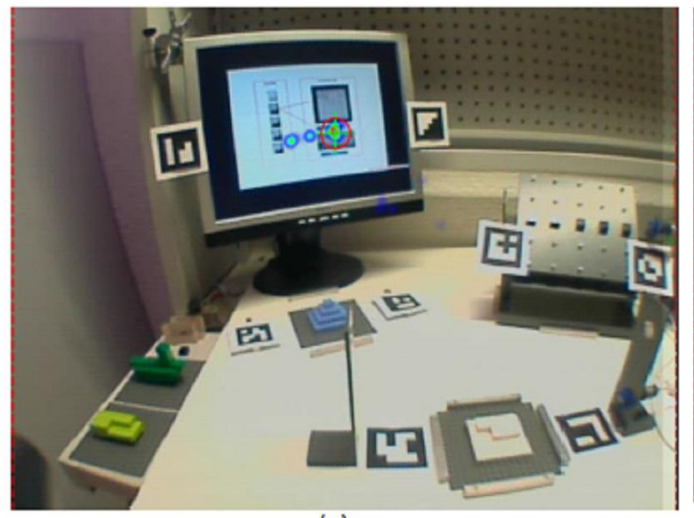

(a)

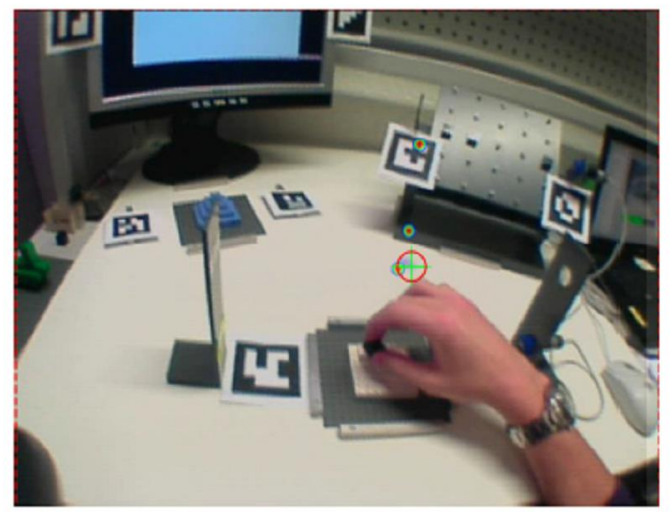

(c)

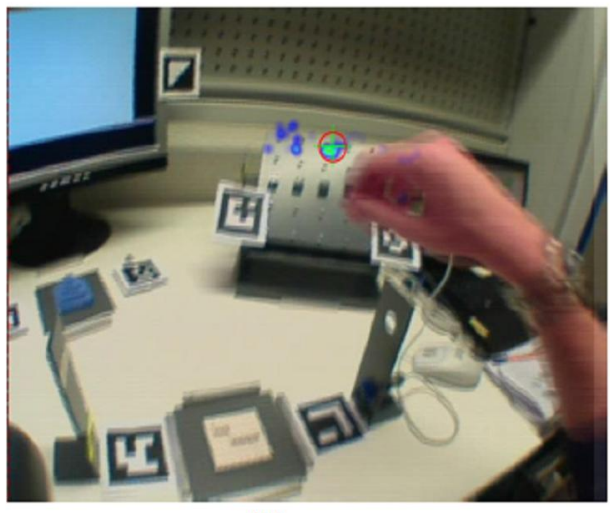

(b)

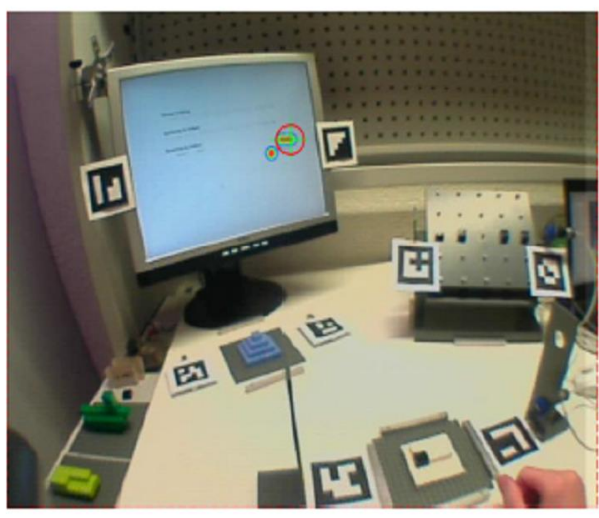

(d)

Figure 4. Heat map analysis of AOI 1(a), AOI 2(b), AOI 3(c) and AOI 1 in subjective evaluation (d) of the product made from LEGO bricks 


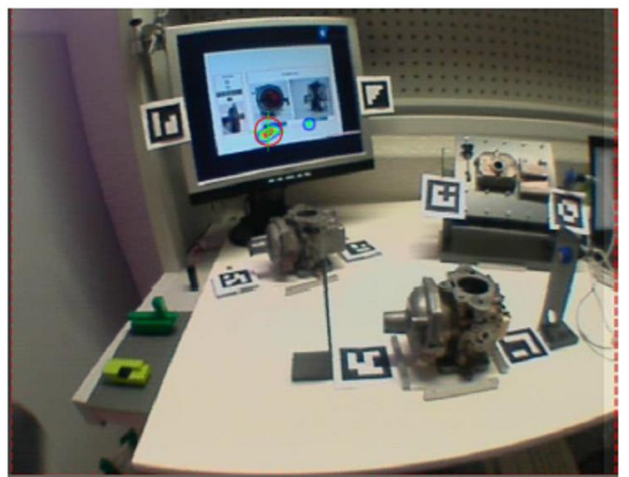

(a)

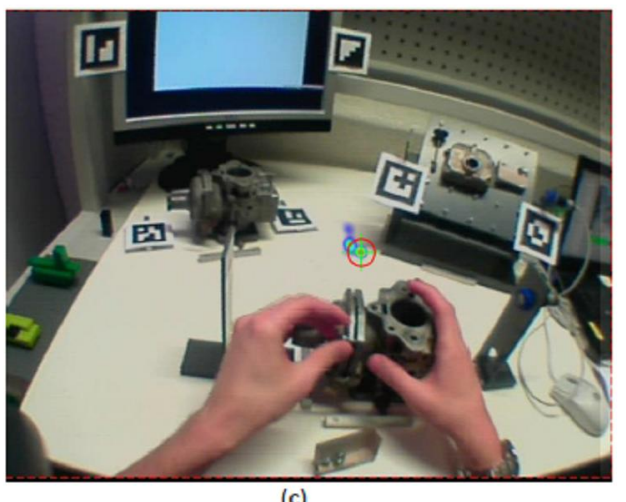

(c)

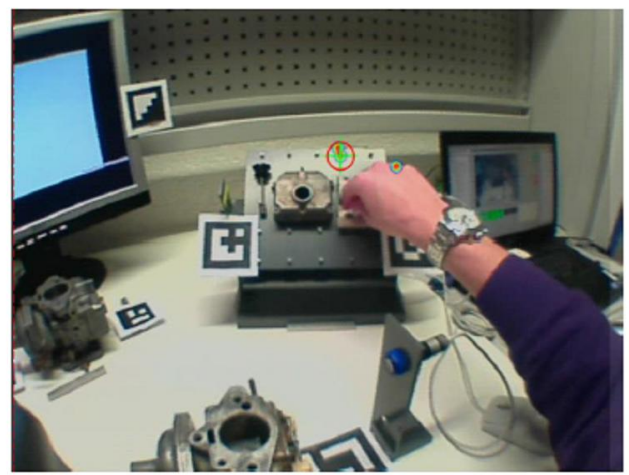

(b)

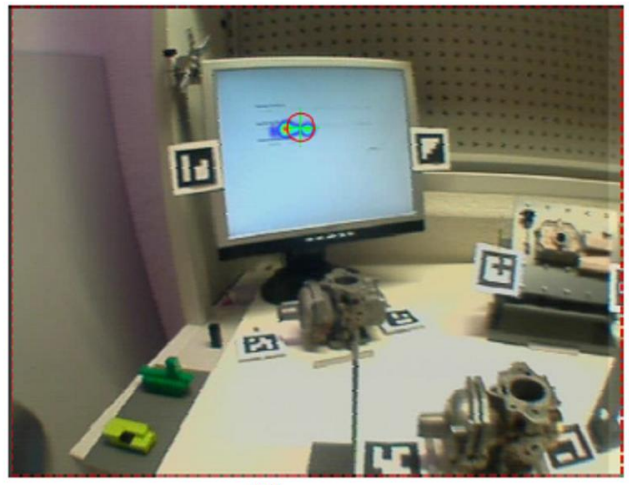

(d)

Figure 5. Heat map analysis of AOI 1(a), AOI 2(b), AOI 3(c) and AOI 1 in a subjective evaluation (d) of the carburetor

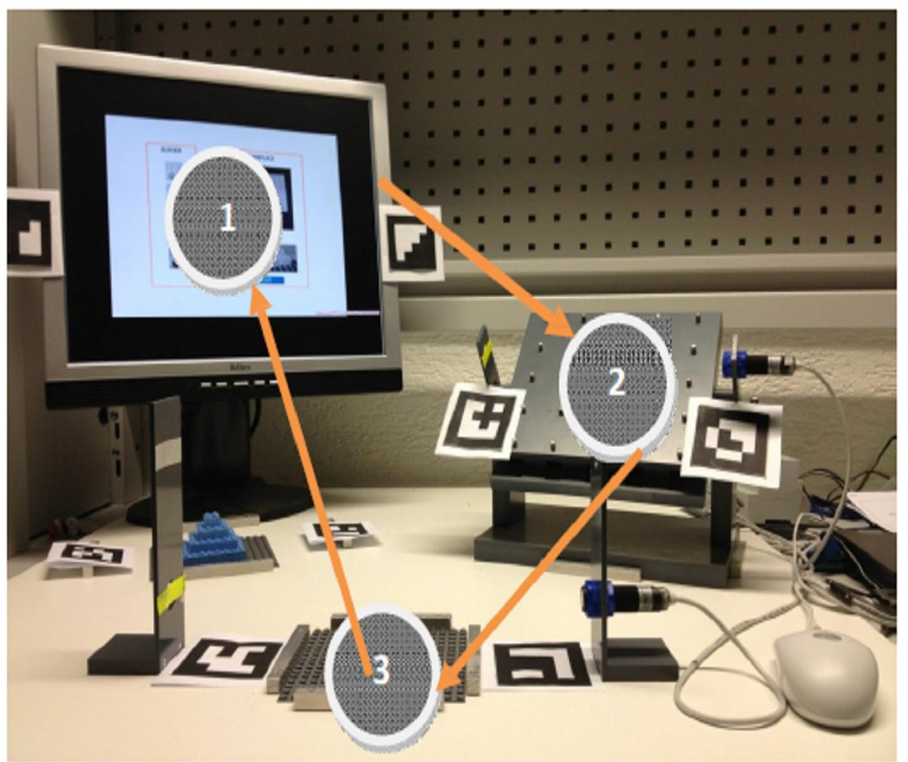

Figure 6. General gaze behavior of participants. 
Table 1. Specific style of the gaze behavior based on AOI

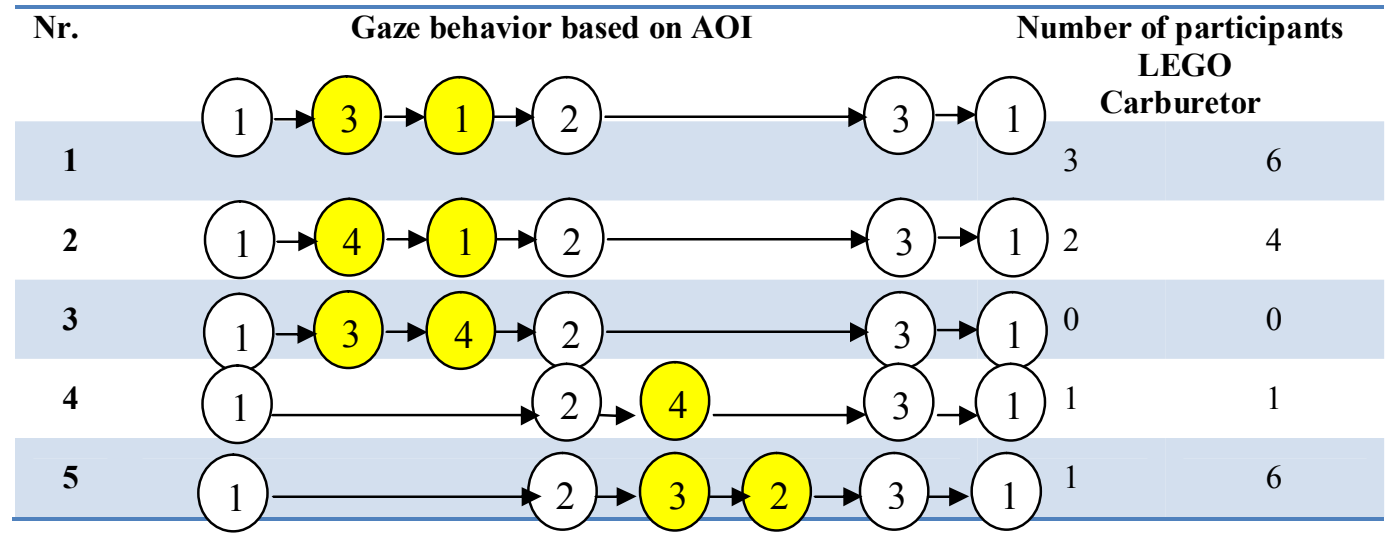

\section{Conclusion}

Based on the analysis of gaze behavior, with regard to AOI 3 we can conclude that the carburetor assembly requires more attention than the product made from LEGO bricks. About $50 \%$ of the participants experience the necessity to visually inspect the interim state of the work object during the simulation of the assembly sequence on the screen. The frequency of attention shifting from AOI 1 to AOI 3 varies between one and four times. In spite of the similar number of participants with the gaze behavior according to type 1 (Table 1 ), the participants exhibit a strong tendency to evaluate the similarity of the actual work object with the simulated object on the screen. In this study, the participants tend to focus on the relationship between the actual work object and the object presented on the screen. They also show the tendency to want to be more certain about part fitting in the actual work object. Thus, the participants pay attention on checking AOI 3 before determining the next part to be assembled.

\section{References}

Buescher, C., Hauck, E., Schilberg, D., and Jeschke, S. (2012). Key Performance Indicators for the Impact of Cognitive Assembly Planning on Ramp-Up Process, Hindawi Publishing Corporation Advances in Decision Sciences Volume 2012, Article ID 798286.

Carlson, T. and Demiris, Y. (2009). Using Visual Attention to Evaluate Collaborative Control Architecture for Human-Robot Interaction. Proceeding of New Frontiers in Human-Robot Interaction: A Symposium at the AISB 2009 Convention. pp. 38-43. SSAISB. EdinburgScotland

Damm, O., Malchus, K., Jaecks, P. and Krach, S. 2013. Different gaze behavior in human-robot interaction in Asperger's syndrome: An eyetracking system. RO-MAN 2013, IEEE 26-29 August 2013 pp. 368-369, Gyeongju.

Gazzola, V., Rizzolatti, G., Wicker, B., and Keysers, C. (2007). The anthropomorphic brain: the mirror neuron system responds to human and robotic actions. NeuroImage 35, pp. 1674-1684.

Mayer, M., Odenthal, B., Faber, M., Winkelholz, C., and Schlick, C. (2012). Cognitive Engineering of Automated Assembly Processes, Human Factors and Ergonomics in Manufacturing and Service Industries. pp 1-21 (online) Wiley Periodical, Inc.

Mayer, M., Odenthal, B., Grandt, M., and Schlick, C. (2008). Task-Oriented Process Planning for Cognitive Production Systems using MTM, Hrsg.:W. Karowski and G. Salvendy, USA Publishing, Las Vegas, Nevada, USA, in: Proceeding of 2nd International Conference on Applied Human Factors and Ergonomic].

Mayer, M., Odenthal, B., Wagels, C., Kuz, S., Kausch, B., and Schlick, C. (2011). Cognitive Engineering of Automated Assembly Processes, Engineering Psychology and Cognitive Ergonomics. Hrsg.: D. Harris. Springer, Berlin 2011, In: Proceeding of 9th International Conference, EPCE 2011, Held as Part of HCI International 2011 Orlando, FL, USA, pp. 313-321.

Mayer, M.P., and Schlick, C. (2012). Improving operator's conformity with expectations in a cognitively automated assembly cell using human heuristics. In: Conference Proceeding of the 4th International Conference on Applied Human Factors and Ergonomics (AHFE), USA Publishing, pp.1263-1272.

Mayer, M.P. (2012). Entwicklung eines kognitions-ergonomischen Konzeptes und eines Simulationssystems für die robotergestützte Montage. Dissertation (in German). Shaker Verlag. Aachen.

Mayer, M.P., Odenthal, B., Faber, M., Neuhöfer, J., Kabuß, W., Kausch, B., and Schlick, C.M. (2009). Cognitive Engineering for Direct Human-Robot Cooperation in Self-optimizing Assembly Cells. M. Kurosu (Ed.): Human Centered Design, HCII 2009, LNCS, 5619, pp. 1003-1012. 
Nisbett and Norenzayan. (2002). Culture and Cognition. Chapter for D. L. Medin (Ed.). Stevens' Handbook of Experimental Psychology, third edition. John Wiley \& Sons, Inc.

OED /Oxford English Dictionary. (2010). Retrieved May 10th, 2010 from dictionary.oed.com.

Schlick, C. Reuth, R., and Luczak, H. (2002). A comparative simulation study of work processes in autonomous production cells. Human Factors and Ergonomics in Manufacturing, 12, pp. 3154.
Susanto, N., Mayer, M., Djaloeis, R., Bützler, J., Schlick, C.(2014). Human-oriented Design of a Cognitive Control Unit for Self-Optimizing Robotic Assembly Cells, In: Proceedings of the 5th International Conference on Applied Human Factors and Ergonomics 2014 (AHFE), Hrsg.: Ahram, T.; Karwowski, W.; Marek, T., The Printing House, Stoughton, FL, USA 2014, ISBN 978-1-4951-1572-1, S. 50585068 . 